\section{International Symposium on Synthesis and Catalysis (ISySyCat2021)}

A quarta edição do congresso International Symposium on Synthesis and Catalysis (ISySyCat2021) decorreu na Universidade de Évora, no Colégio do Espírito Santo (CES), entre 31 de agosto e 3 de setembro de 2021. Devido à pandemia da COVID-19 o congresso foi organizado de forma híbrida: presencial e online. Apesar das dificuldades encontradas na organização de eventos públicos, principalmente ao nível internacional durante os últimos 18 meses, o congresso foi um grande sucesso. Investigadores pertencentes a várias instituições académicas e também membros ativos da indústria química participaram entusiasticamente neste evento. 0 foco do simpósio foi a síntese química e

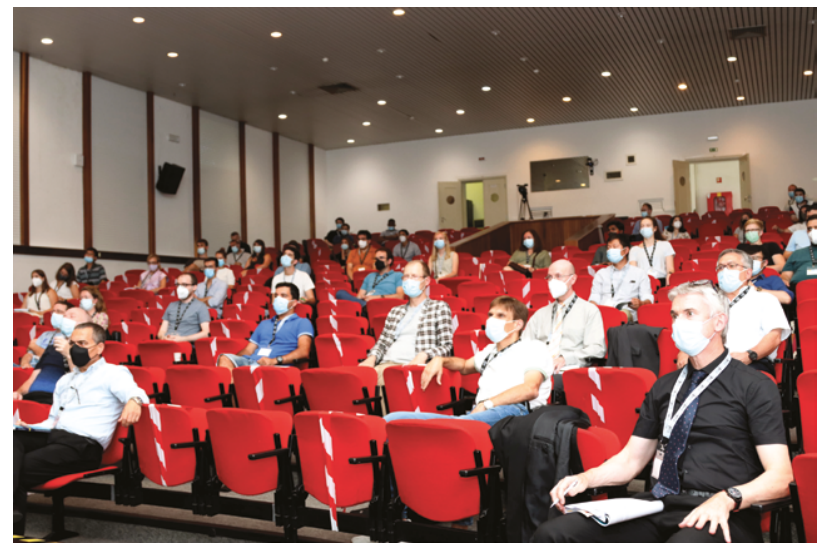

Visão geral do auditório do CES durante uma sessão plenária. Crédito: Carlos Espiga, Divisão de Comunicação, Universidade de Évora.

catálise e as sinergias nestas áreas entre a investigação académica e a indústria. 0 congresso destacou-se pelo seu excelente programa tanto a nível cientíico como a nível social. A promoção do diálogo entre a investigação académica e a indústria foi uma preocupação constante durante o congresso, sempre com a perspetiva dos benefícios de que daí podem advir, nomeadamente mais inovação e melhor competitividade, proveitos para as empresas e geração de emprego, com os consequentes benefícios gerais para a sociedade.

O programa científico contou com 13 lições plenárias, mais de 70 comunicações orais e flash talks e quase 90 comunicações em painel. Os oradores presentes, muitos deles de renome internacional, abordaram vários temas, nomeadamente: síntese total de produtos naturais; síntese na química medicinal e na química biológica; química prebiótica; desenvolvimento de processos para a síntese de fármacos; novos reagentes e catalisadores; estratégias e conceitos para a síntese orgânica; biocatálise; organocatálise; aplicação de química de fluxo contínua na síntese de moléculas-alvo; aplicação de compostos organometálicos na síntese e catálise; síntese estereosseletiva; síntese e propriedades de moléculas funcionais e materiais orgânicos; síntese e métodos catalíticos sustentáveis; ferramentas computacionais para a biocatálise.

0 congresso premiou os participantes que apresentaram trabalhos de destaque, tendo sido atribuídos um prémio para a melhor comunicação oral (patrocinada pela Wiley-VCH) e três prémios para comunicações em painel (patrocinados pela Royal Society of Chemistry).

No que se refere ao programa social, durante os quatro dias do evento, houve sempre espaço para o convívio e discussão dos temas do congresso entre os participantes nos coffee breaks, a receção social e o jantar do congresso. Houve ainda ocasião para visitar a histórica cidade de Évora e a adega João Portugal Ramos em Estremoz que incluiu almoço, degustação de vinhos e visita à adega.

A quarta edição do congresso ISySyCat superou os seus objetivos e foi um sucesso considerando as circunstâncias. 0 feedback recebido dos congressistas durante e após o congresso foi extremamente positivo e motivador para se proceder à organização da quinta edição do ISySyCat em 2023, o ISySyCat2023, que vai decorrer entre 5 e 8 de setembro de 2023.

A Comissão Organizadora agradece a todas as pessoas e entidades que colaboraram, tornaram possível e contribuíram indubitavelmente para o sucesso deste congresso, nomeadamente os patrocinadores e instituições que apoiaram o evento. Uma palavra de reconhecido agradecimento é devida à Universidade de Évora e à Sociedade Portuguesa de Química. Por último, um agradecimento a todos os participantes que, com as suas contribuições, garantiram a qualidade do ISySyCat2021.

\section{$>$}

\section{A Comissão Organizadora}

isysycat2021@chemistry.pt

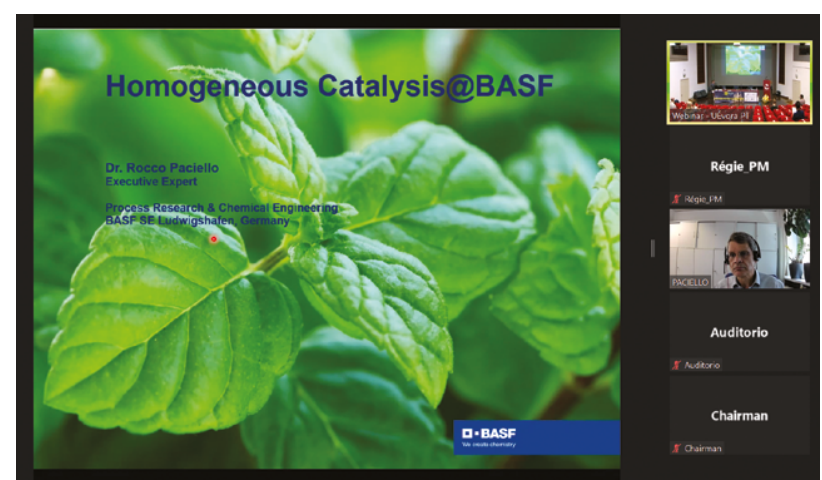

Lição plenária do Dr. Rocco Paciello, Executive Expert da BASF. 